\title{
₹USGS
}

science for a changing world

Prepared in cooperation with the U.S. Fish and Wildlife Service

\section{Evaluation of the Genetic Distinctiveness of Greater Sage-Grouse in the Bi-State Planning Area}

By Sara J. Oyler-McCance and Michael L. Casazza

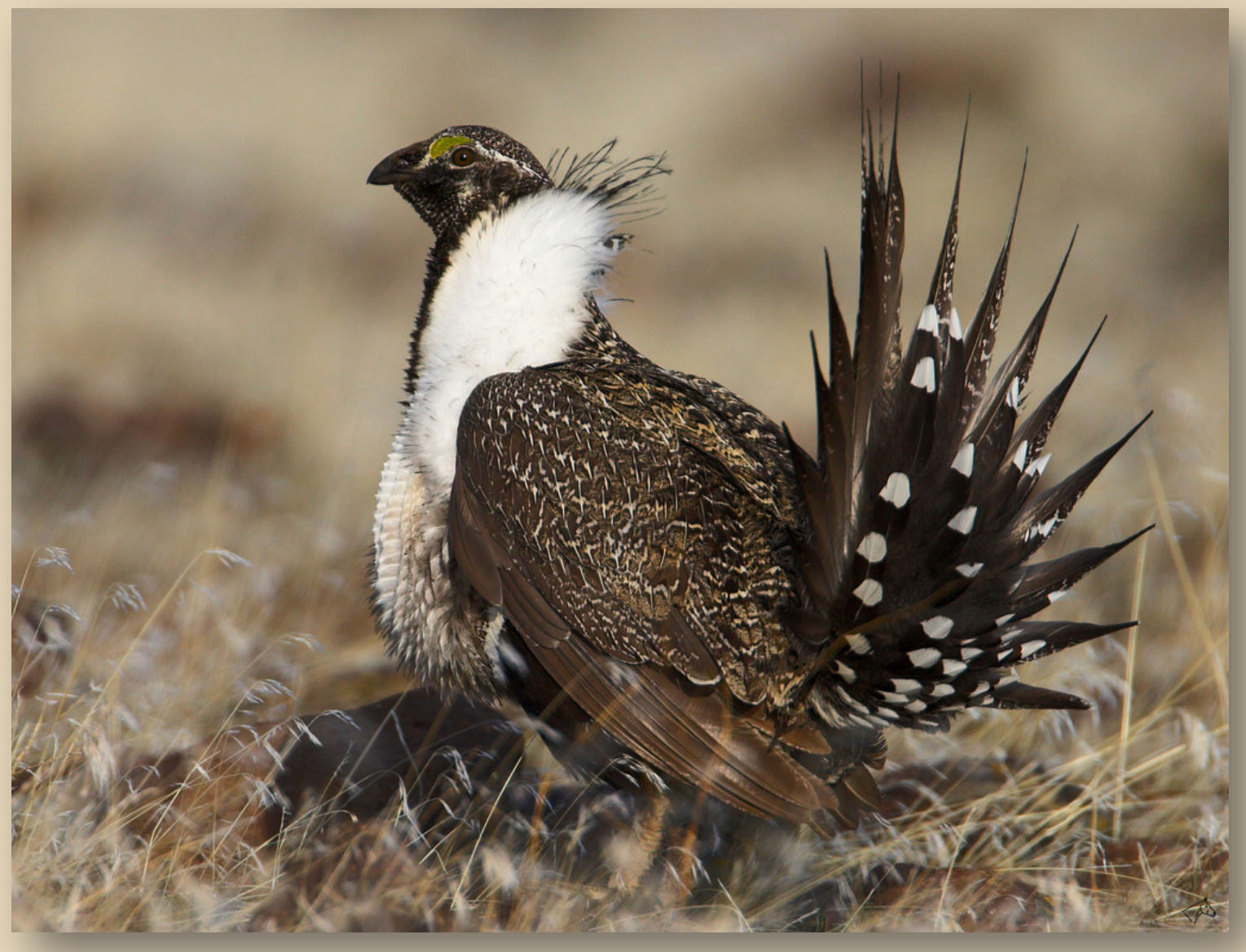

Open-File Report 2011-1006

U.S. Department of the Interior

U.S. Geological Survey 


\section{U.S. Department of the Interior \\ KEN SALAZAR, Secretary}

\section{U.S. Geological Survey \\ Marcia K. McNutt, Director}

U.S. Geological Survey, Reston, Virginia 2011

For product and ordering information:

World Wide Web: http://www.usgs.gov/pubprod

Telephone: 1-888-ASK-USGS

For more information on the USGS-the Federal source for science about the Earth,

its natural and living resources, natural hazards, and the environment:

World Wide Web: http://www.usgs.gov

Telephone: 1-888-ASK-USGS

Suggested citation:

Oyler-McCance, S.J. and Casazza, M.L., 2011, Evaluation of the genetic distinctiveness of Greater Sage-grouse in the Bi-State Planning Area: U.S. Geological Survey Open-File Report 2011-1006, 15 p.

Any use of trade, product, or firm names is for descriptive purposes only and does not imply endorsement by the U.S. Government.

Although this report is in the public domain, permission must be secured from the individual copyright owners to reproduce any copyrighted material contained within this report.

Cover photo: Greater Sage-grouse, courtesy of Stephen Ting/USFWS 


\section{Contents}

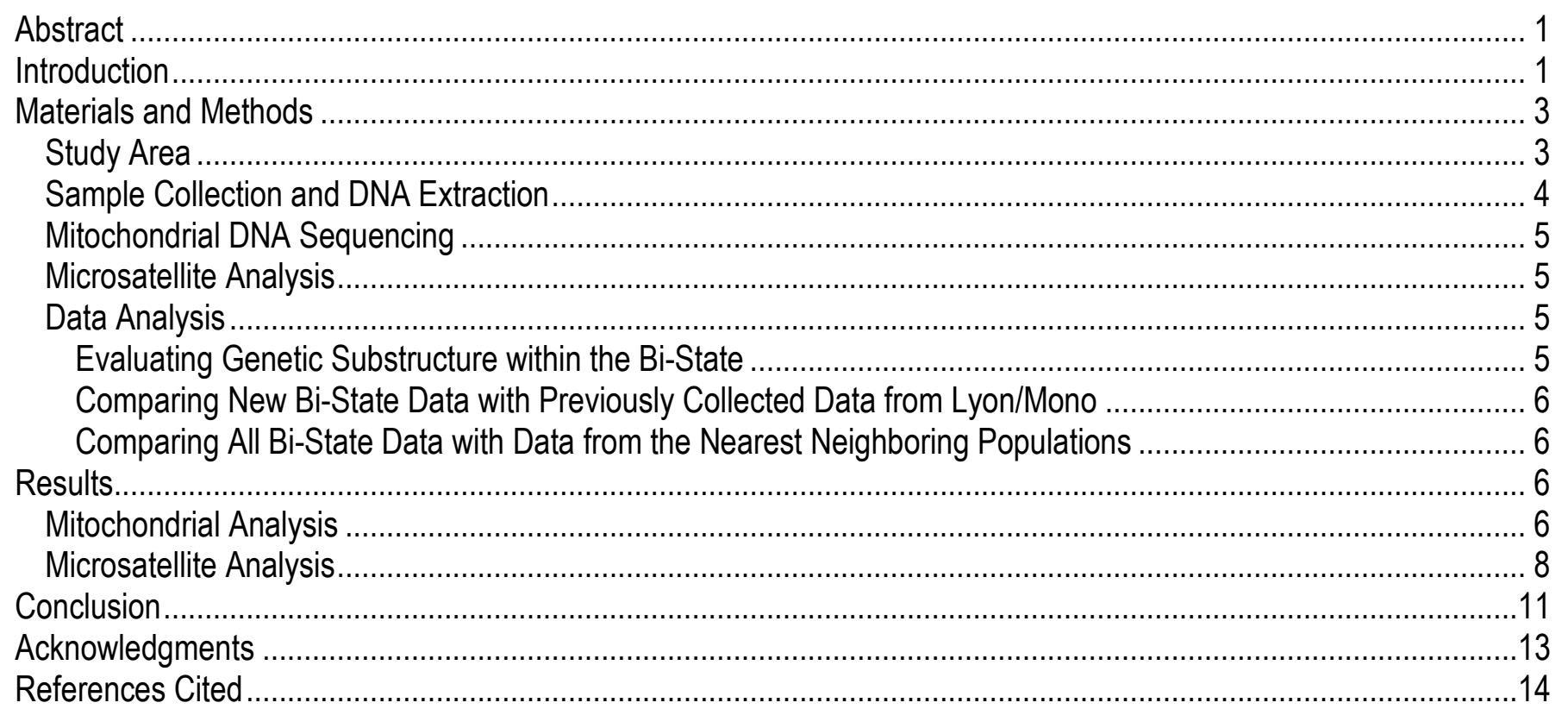




\section{Figures}

1. Map of historic and current range of the Greater Sage-grouse with the Bi-State Planning Area circled in blue and Churchill and Lassen sampling areas in red (modified from Schroeder and others 2004). The dots represent areas that were sampled previously

2. Map of the Bi-State Planning Area with the six subpopulations sampled in this study labeled.

3. Neighbor-joining tree showing the phylogenetic relationship among all Greater Sage-grouse haplotypes. Bootstrap values over 60 are shown. Clade 1 (previously described in Kahn and others 1999) is the lower clade. Haplotypes unique to the Bi-State Planning Area are shown in red, those shared with Greater Sagegrouse outside of the Bi-State planning area shown in blue. Blue grouse is used as an outgroup

4. STRUCTURE results for $K=3$ with populations: (1) Jackass Flat, (2) Wheeler Burcham Flat, (3) Bodie Hills, (4) Parker Meadows, (5) Long Valley, and (6) White Mountain. Subpopulations are shown in order from north to south. Each bar represents an individual sage-grouse. Different colors of the bar represent the probability of belonging to the cluster of that color

5. STRUCTURE results for $K=4$ with populations: (1) Jackass Flat, (2) Wheeler Burcham Flat, (3) Bodie Hills, (4) Parker Meadows, (5) Long Valley, (6) White Mountain (7) Lyon/Mono, (8) Lassen, and (9) Churchill. Each bar represents an individual sage-grouse. Different colors of the bar represent the probability of belonging to the cluster of that color.

\section{Tables}

1. Genetic diversity measures using mitochondrial DNA for the six subpopulations included in this study

2. Haplotypes present in each subpopulation within the Bi-State Planning Area and three populations from Oyler-McCance and others (2005a). The Lassen and Churchill populations are outside of the Bi-State Planning Area yet are the nearest neighboring populations.

3. Pairwise population $F_{S T}$ comparisions using mitochondrial DNA data ...................................................... 10

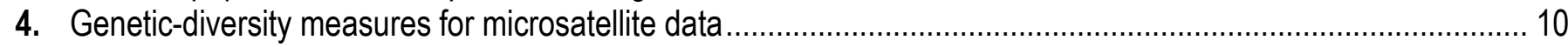

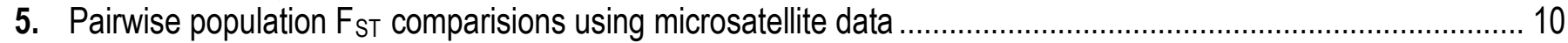




\title{
Evaluation of the Genetic Distinctiveness of Greater Sage-Grouse in the Bi-State Planning Area
}

\author{
By Sara J. Oyler-McCance and Michael L. Casazza
}

\begin{abstract}
The purpose of this study was to further characterize a distinct population of Greater Sagegrouse: the population located along the border between Nevada and California (Bi-State Planning Area) and centered around the Mono Basin. This population was previously determined to be genetically distinct from other Greater Sage-grouse populations across their range. Previous genetic work focused on characterizing genetic variation across the species' range and thereby used a coarse sampling approach for species characterization. The goal of this study was to investigate this population further by obtaining samples from breeding locations within the population and analyzing those samples with the same mitochondrial and microsatellite loci used in previous studies. Blood samples were collected in six locations within the Bi-State Planning Area. Genetic data from subpopulations were then compared with each other and also with two populations outside of the Bi-State Planning Area. Particular attention was paid to subpopulation boundaries and internal dynamics by drawing comparisons among particular regions within the Bi-State Planning Area and regions proximal to it. All newly sampled subpopulations contained mitochondrial haplotypes and allele frequencies that were consistent with the genetically unique Bi-State (Mono Basin) Greater Sage-grouse described previously. This reinforces the fact that this group of Greater Sage-grouse is genetically unique and warrants special attention. Maintaining the genetic integrity of this population could protect the evolutionary potential of this population of Greater Sage-grouse. Additionally, the White Mountains subpopulation was found to be significantly distinct from all other Bi-State subpopulations.
\end{abstract}

\section{Introduction}

Greater Sage-grouse (Centrocercus urophasianus) are ground-dwelling galliforms found exclusively in North America. Historically, they occupied virtually any habitat dominated by sagebrush (Artemisia tridentata), including much of the western United States (Johnsgard, 1983). Because of the loss, fragmentation, and degradation of sagebrush habitat, Greater Sage-grouse populations have declined dramatically (Braun, 1998), resulting in the isolation of small populations from larger populations which exist in more contiguous habitat (fig. 1). Many of the populations that are currently small and isolated (such as in Washington and Utah) were historically much larger and well connected (fig. 1). The one exception is the population of Greater Sage-grouse that exists in the sagebrush habitat along the border between Nevada and California identified as the Bi-State Planning Area (Bi-State Local Planning Group, unpublished conservation plan), hereafter referred to as "Bi-State", centered on the Mono Basin (fig. 1). This narrow peninsula of sagebrush is surrounded on most sides by mountain ranges and is geographically isolated from other Greater Sage-grouse populations, yet not due to significant loss of sagebrush habitat (fig. 1). Rather, this population appears to have been largely isolated through geographic and landscape features since before English settlement (Schroeder and 


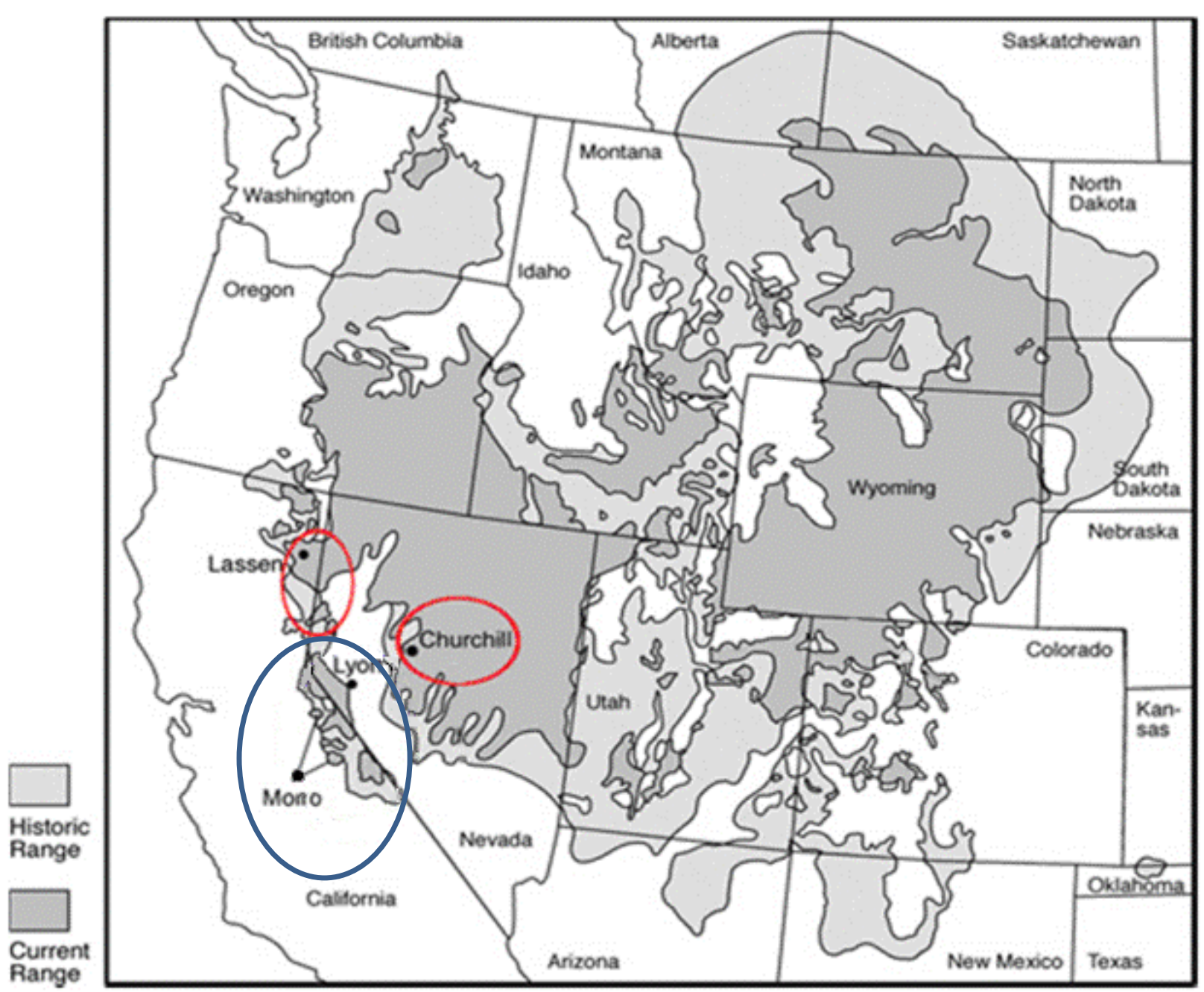

Figure 1. Map of historic (light gray) and current (dark gray) range of the Greater Sage-grouse with the Bi-State Planning Area circled in blue and Churchill and Lassen sampling areas in red (modified from Schroeder and others, 2004). The dots represent areas that were sampled previously (Lassen, Churchill, Lyon and two areas collectively referred to as Mono). Note the dark-gray-colored sagebrush pockets (separated from other dark gray areas) in the Bi-State Planning Area.

others, 2004). The only area where this population was once connected to the rest of the species' range was a narrow patch of sagebrush north of the Bi-State area, near Lassen, Calif., that has now been lost through habitat conversion.

A previous study of Greater Sage-grouse characterized genetic variation across the species' range. This study revealed that the distribution of genetic variation showed a gradual shift across the range in both mitochondrial and nuclear markers, suggesting that in general, movements of the Greater Sage-grouse were typically among neighboring populations and not across the species' range (OylerMcCance and others, 2005a). The Bi-State population, however, was an exception to this pattern as it was found to be genetically distinct because it is characterized by a high proportion of unique mitochondrial DNA (mtDNA) haplotypes (Benedict and others, 2003; Oyler-McCance and others, 
2005a) and has significant population differentiation as measured using microsatellite analysis (OylerMcCance and others, 2005a). As a result of these findings, Oyler-McCance and others (2005a) suggested that the Greater Sage-grouse in the Bi-State warranted special attention and added that maintaining the genetic integrity of this population could protect the evolutionary potential of this population of Greater Sage-grouse. Concern for the survival of small, isolated populations and how they may be affected by catastrophes and environmental factors has created a need for closer examination of this population.

Previous genetic research on this population studied only limited numbers of birds from one sampling location in Lyon County, Nevada, and two locations in Mono County, California. This sampling effort included only a portion of the geographically isolated area (fig. 1). Further, samples were obtained from hunter-killed Greater Sage-grouse shot in the fall, such that the breeding location (that is, location of leks attended) of those birds was unknown. The extent of the birds' movement among discrete areas of sagebrush within the Lyon/Mono region (fig. 1) remains unknown, as does the specific boundaries of the genetically distinct population. To address these issues and to look at the population's subdivision within this region, six distinct breeding locations of Greater Sage-grouse within the Bi-State were targeted for sampling with the goal of analyzing samples using the same techniques used in previous studies (Benedict and others, 2003; Oyler-McCance and others, 2005a). This information could then be used to characterize genetic variation at a finer scale within the Bi-State and could be compared to other Greater Sage-grouse populations neighboring the Bi-State population. Our specific objectives were to (1) determine whether there was genetic structure among the subpopulations sampled within the Bi-State, (2) determine whether all subpopulations within the BiState carried the unique Lyon/Mono genetic signature defined previously, and (3) compare all data (new and previously analyzed) within the Bi-State with the nearest neighboring Greater Sage-grouse populations.

\section{Materials and Methods}

\section{Study Area}

The Bi-State area straddles the border between Nevada and California and is separated from other continuous sagebrush habitat in both states (fig. 1). It is comprised of smaller, discrete patches of sagebrush and is surrounded by mountain ranges that may segregate subpopulations of Greater Sagegrouse from one another. The areas sampled in this study included Jackass Flat (JF), Wheeler Burcham Flat (WBF), Bodie Hills (BH), Parker Meadows (PM), Long Valley (LV), and White Mountains (WM) (fig. 2).

In order to compare these new data to previously analyzed samples from the Bi-State as well as with the two populations most proximal to the Bi-State, data from individuals from three areas analyzed previously (Oyler-McCance and others, 2005a) were included in this analysis (see fig. 1). Sample sizes for each of these three populations differed between the mtDNA and the microsatellite analyses and are described below. These data include individuals from the two closest neighboring populations in Churchill, Nev. and Lassen, Calif., as well a group of individuals collected originally from Lyon County, Nev., and Mono County, Calif. (hereafter Lyon/Mono) (fig. 1). It is important to note that the genetic make-up of both the Churchill and Lassen populations was typical of Greater Sage-grouse in the western part of the range, while the genetic make-up of the Lyon/Mono population was determined to be unique (Benedict and others, 2003; Oyler-McCance and others, 2005a). 
Greater Sage-Grouse Genetic Sampling Locations

Bi-State and Adjacent Management Units

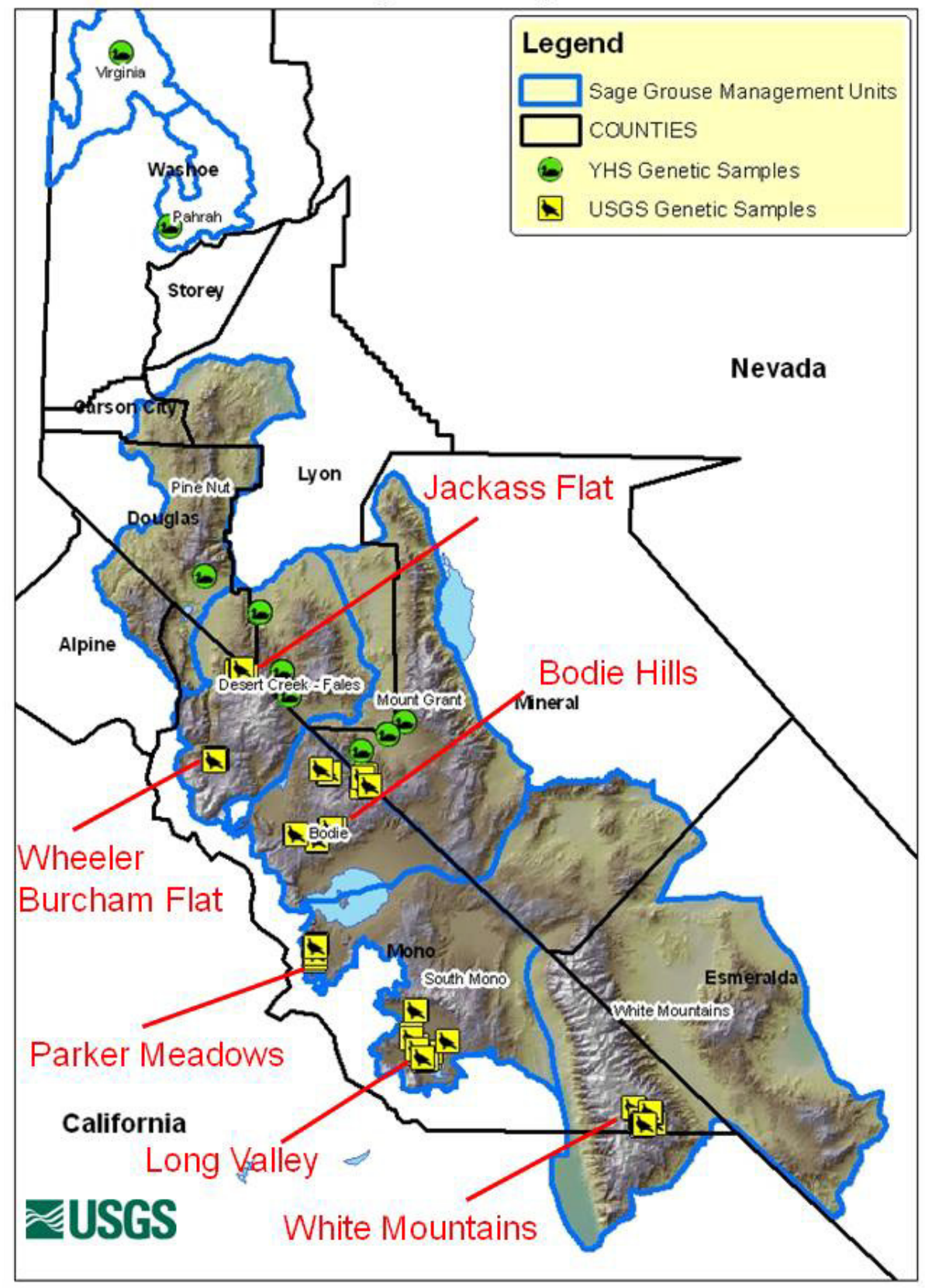

Figure 2. Map of the Bi-State Planning Area with the six subpopulations sampled in this study labeled.

\section{Sample Collection and DNA Extraction}

One hundred and ten birds from six areas within the Bi-State were included in this study. Blood samples were obtained from Greater Sage-grouse captured using a spotlight trapping method (Giesen and others, 1982). The toenail of each bird was clipped and several drops of blood were placed in an EDTA-coated, $1.5-$ milliliter $(\mathrm{mL})$ Eppendorf tube (Brinkman) and stored at $-20^{\circ} \mathrm{C}$. DNA was extracted 
using the GenomicPrep Blood DNA Isolation Kit (General Electric) with modifications following Oyler-McCance and others (2005b).

\section{Mitochondrial DNA Sequencing}

A 146 base-pair portion of hypervariable control region I was amplified using the Polymerase Chain Reaction (PCR) and sequenced using a dye-terminator cycle-sequencing reaction (Beckman Coulter CEQ 8000) as described by Benedict and others (2003). This region was used because it was known to contain approximately 92 percent of the variable sites in a larger 380 base-pair region spanning control region I (Kahn and others, 1999). Sequences were edited and aligned with Sequencher 4.2 (GeneCodes) and compared to known, previously-published haplotypes (Kahn and others, 1999; Benedict and others, 2003; Oyler-McCance and others, 2005a). For the mtDNA analysis, we included data from individuals analyzed previously (Oyler-McCance and others, 2005a) from Churchill, Nev. ( $n$ $=18)$, Lassen, Calif. $(n=22)$, and Lyon/Mono $(n=54)$.

\section{Microsatellite Analysis}

Seven nuclear microsatellite loci (LLST1, SGCA5, SGCA9, SGCA11, LLSD3, LLSD8, and ADL0230) were screened using the methods described in Oyler-McCance and others (2005a). To briefly describe the method, PCR reactions were performed using a dye-labeled forward primer; amplified products were then run on the CEQ 8000 Genetic Analysis System (Beckman Coulter). For the microsatellite analysis, we included data from individuals analyzed previously (Oyler-McCance and others, 2005a) from Churchill, Nev. $(n=22)$, Lassen, Calif. $(n=55)$, and Lyon/Mono $(n=68)$.

\section{Data Analysis}

A number of different analyses were used to investigate the three different objectives of this study. These methods are described in further detail by objective below.

\section{Evaluating Genetic Substructure within the Bi-State}

All mtDNA sequences were edited and aligned using Sequencher Version 4.1.4, and haplotypes (unique DNA sequences) were identified through comparison with previous mtDNA work (OylerMcCance and others, 2005a). A neighbor-joining tree was generated in MEGA version 4.0 (Tamura and others, 2007) in the non-coding mode using the complete-deletion option and the Kimura 2 parameter model of mutation. One thousand bootstrap replicates were conducted. For an outgroup, we used a blue grouse (Dendragapus obscurus) control-region sequence that was published in Genbank (Accession number AY570356.1). Measures of mtDNA genetic diversity were calculated in Arlequin 2.001 (Schneider and others, 2001) as were pairwise subpopulation $\mathrm{F}_{\mathrm{ST}}$ tests. Subpopulations were deemed to be significantly different using a Bonferroni corrected $\mathrm{P}$ value of 0.001 , that corrects the $\mathrm{P}$ value due to multiple comparisons.

The mean number of microsatellite alleles (unique variants) for each subpopulation was calculated and the observed and expected levels of heterozygosity were estimated using Genalex (Peakall and Smouse, 2006). Allelic richness, which adjusts for discrepancies in sample size by incorporating a rarefaction method, was estimated in FSTAT 2.9.3.2 (Goudet, 1995). Microsatellite loci were tested (by subpopulation) for departures from Hardy-Weinberg equilibrium (Guo and Thompson, 1992) using the computer program Arlequin 2.001 (Schneider and others, 2001). Pairwise subpopulation genetic distances $\left(\mathrm{F}_{\mathrm{ST}}\right)$ were calculated in Arlequin 2.001 (Schneider and others, 2001). Subpopulations were deemed to be significantly different using a Bonferroni corrected $\mathrm{P}$ value of 0.001 . 
Subpopulation structure was also examined using STRUCTURE 2.00 software (Pritchard and others, 2000). In this program, individuals are grouped into clusters without regard to the assigned subpopulation using a model-based clustering analysis. The number of unique genetic clusters $(\mathrm{K})$ was initially estimated by conducting five independent runs each of $K=1-10$ with 100,000 Markov Chain Monte Carlo (MCMC) repetitions and a 100,000 burnin period using the model with admixture, correlated allele frequencies, and no prior information. An additional set of five independent runs was then conducted with $\mathrm{K}=1-7$ with 500,000 MCMC repetitions and a 250,000 burnin period using the above model. The most appropriate value of $\mathrm{K}$ was determined by choosing the smallest value of $\mathrm{K}$ before the log-likelihood estimates plateau.

\section{Comparing New Bi-State Data with Previously Collected Data from Lyon/Mono}

To determine whether the newly collected data from the Bi-State were characteristic of the unique Lyon/Mono signature described previously (Benedict and others, 2003; Oyler-McCance and others, 2005a), we compared the distribution of mtDNA haplotypes and microsatellite allele frequencies in the newly collected data with those of the original Lyon/Mono samples. For these analyses, we treated each measured subpopulation within the Bi-State as a true population and calculated pairwise population $\mathrm{F}_{\mathrm{ST}}$ tests using both the mtDNA and the microsatellite data.

\section{Comparing All Bi-State Data with Data from the Nearest Neighboring Populations}

To investigate how the Bi-State birds (including the original Lyon/Mono samples) compared to birds in the closest populations outside the Bi-State, we again compared the distributions of mtDNA haplotypes and microsatellite alleles for all Bi-State birds with the Churchill and Lassen populations. For these analyses, we treated each subpopulation within the Bi-State as a true population and calculated pairwise population $\mathrm{F}_{\mathrm{ST}}$ tests using both the mtDNA and the microsatellite data. Additionally, we used the program STRUCTURE (Pritchard and others, 2000) to estimate the most appropriate number of unique genetic clusters given the data. We initially estimated $\mathrm{K}$ by conducting five independent runs each of $\mathrm{K}=1-10$ with 100,000 Markov Chain Monte Carlo (MCMC) repetitions and a 100,000 burnin period using the model with admixture, correlated allele frequencies, and no prior information. An additional set of five independent runs was then conducted with $\mathrm{K}=1-7$ with 500,000 MCMC repetitions and a 250,000 burnin period using the above model. The most appropriate value of $\mathrm{K}$ was determined by choosing the smallest value of $\mathrm{K}$ before the log-likelihood estimates plateau.

\section{Results}

\section{Mitochondrial Analysis}

Of the 110 individuals sequenced in this study, we found 11 haplotypes in the Bi-State with two being new (not described previously in Oyler-McCance and others (2005a)). The two new haplotypes were each only one substitution different from a previously described haplotype (Oyler-McCance and others, 2005a). All haplotypes belonged to one of the two deeply divergent clades identified previously (Kahn and others, 1999), with the two new haplotypes both belonging to clade I (fig. 3). Among the six subpopulations newly analyzed here, the average number of haplotypes per subpopulation was 4.33. Subpopulation PM had only two haplotypes (BM and BJ), and hence had a small gene diversity of only 0.2821 (table 1). Of the Bi-State subpopulations, JF had the highest gene diversity (0.7714), LV had the highest number of haplotypes (6), and JF and $\mathrm{BH}$ were tied for second (5; table 1). 


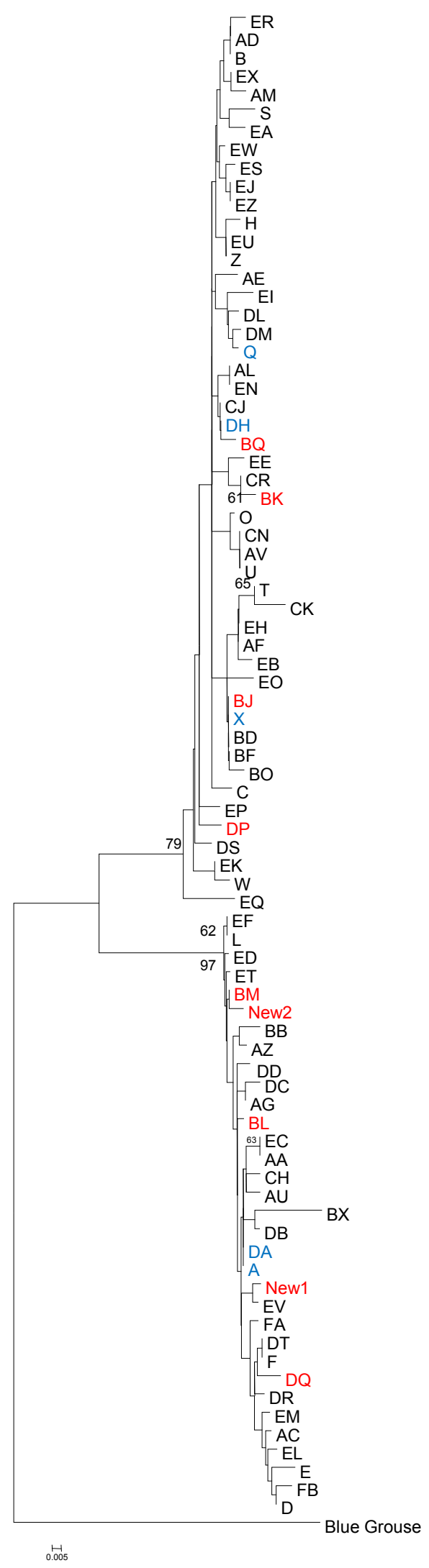

Figure 3. Neighbor-joining tree showing the phylogenetic relationship among all Greater Sage-grouse haplotypes. Bootstrap values over 60 are shown. Clade 1 (previously described in Kahn and others (1999)) is the lower clade. Haplotypes unique to the Bi-State Planning Area are shown in red, those shared with Greater Sagegrouse outside of the Bi-State planning area shown in blue. Blue grouse is used as an outgroup. 
Table 1. Genetic diversity measures using mitochondrial DNA for the six subpopulations included in this study.

\begin{tabular}{lccc}
\hline Population & $\begin{array}{c}\text { Number of } \\
\text { samples }\end{array}$ & Gene diversity & Number of haplotypes \\
\hline Long Valley & 15 & 0.7429 & 6 \\
Bodie Hills & 30 & 0.7540 & 5 \\
Wheeler Burcham Flat & 8 & 0.7500 & 4 \\
Parker Mountain & 13 & 0.2821 & 2 \\
White Mountains & 29 & 0.7241 & 4 \\
Jackass Flat & 15 & 0.7714 & 5 \\
\hline
\end{tabular}

Haplotypes X, A, DH and DA were the only haplotypes found in the Bi-State in this study that have ever been reported outside of the Bi-State (haplotype DA was found previously in Elko, Nev.). Of the 110 individuals sampled, only 14 (13 percent) had haplotypes that were shared with Greater Sagegrouse outside the Bi-State (table 2). The most frequently occurring haplotype in the Bi-State in this study was BJ-it occurred in 32 individuals (table 2). This haplotype was also the most frequently occurring from the original Lyon/Mono samples. The nine haplotypes that are unique to the Bi-State were found in both clades (fig. 3) and are not closely related to one another.

Pairwise population comparisons $\left(\mathrm{F}_{\mathrm{ST}}\right)$ showed no significant differences between the previously collected Lyon/Mono samples and all other newly collected Bi-State subpopulations (table 3 ). The Churchill population was significantly different from all the Bi-State subpopulations except $\mathrm{PM}(P<$ $0.001)$.

\section{Microsatellite Analysis}

There was only one significant departure from Hardy Weinberg Equilibrium in subpopulation LV with the SGCA9 locus $(P<0.0001)$. The average number of microsatellite alleles per subpopulation ranged from 3 to 4.85 for the samples analyzed in this study and from 5.6 to 6.4 in the Lyon/Mono, Lassen, and Churchill populations (Oyler-McCance and others (2005a)). Parker Mountain (PM) and Wheeler Burcham Flat (WBF) had the lowest average number of alleles per locus at 3.0, yet when we correct for differences in sample size, WBF and WM had the lowest allelic richness (table 4). The range of allelic-richness values across all subpopulations is small (table 4).

Pairwise population $\mathrm{F}_{\mathrm{ST}}$ tests revealed that among subpopulations, most were significantly different from only a few other subpopulations, with the exception of WM, which was significantly different from all other subpopulations. When comparing each subpopulation to the 68 Lyon/Mono samples previously collected, only WM was significantly different (table 5). Upon comparing all BiState birds to Churchill and Lassen, all subpopulations as well as the previously collected Lyon/Mono samples were significantly different.

The STRUCTURE analysis estimated the most likely number of unique genetic clusters (K) given the data and then assigned each individual a probability of belonging to each of those $\mathrm{K}$ clusters. The most appropriate number of unique genetic clusters for the newly collected data ( $\mathrm{LV}, \mathrm{BH}, \mathrm{WBF}$, PM, WM, JF) was 3 (fig. 4). The WM subpopulation appeared to be different than the other subpopulations - in the WM subpopulation, most individuals have a high probability of belonging to the genetic cluster represented in red (fig. 4). A second STRUCTURE analysis that included previously collected samples from Lyon/Mono, Churchill, and Lassen revealed that the most likely value of $\mathrm{K}$ given that data set was 4 (fig. 5). Individuals from Churchill and Lassen were similar to each other, yet different from the Bi-State individuals in that they were largely assigned to a genetic cluster represented in red. Again, the WM subpopulation appeared somewhat different from other Bi-State birds, being characterized largely by assignment in the genetic cluster represented in blue (fig. 5). The remaining BiState birds were variable in their cluster assignments (fig. 5). 
Table 2. Haplotypes present in each subpopulation within the Bi-State and three populations from Oyler-McCance and others (2005a). The Lassen and Churchill populations are outside of the Bi-State yet are the nearest neighboring populations. [LV, Long Valley; BH, Bodie Hills; WBF, Wheeler Burcham Flat; PM; Parker Meadows, WM, White Mountains; JF, Jackass Flat]

\begin{tabular}{|c|c|c|c|c|c|c|c|c|c|c|c|c|c|c|c|c|c|c|c|c|c|c|c|}
\hline & \multirow[b]{2}{*}{$N$} & \multicolumn{22}{|c|}{ Haplotypes } \\
\hline & & A & B & $Q$ & $T$ & $x$ & $A Z$ & AV & $B D$ & BF & BJ & BK & $\mathrm{BL}$ & BM & $B Q$ & DA & $\mathrm{DH}$ & $\mathrm{DL}$ & DM & DP & $\begin{array}{l}D \\
Q\end{array}$ & New1 & New2 \\
\hline LV & 15 & & & & & 1 & & & & & 1 & & 7 & 1 & & & & & & 4 & & & 1 \\
\hline $\mathrm{BH}$ & 30 & & & & & & & & & & 13 & & 5 & 5 & & & 3 & & & & 4 & & \\
\hline WBF & 8 & & & & & & & & & & 1 & & & 4 & & & 2 & & & & 1 & & \\
\hline PM & 13 & & & & & & & & & & 11 & & & 2 & & & & & & & & & \\
\hline WM & 29 & & & & & 6 & & & & & & & & 12 & & & & & & 8 & & 3 & \\
\hline $\mathrm{JF}$ & 15 & 1 & & & & & & & & & 6 & & & 3 & & 1 & & & & & 4 & & \\
\hline $\begin{array}{l}\text { Lyon/ } \\
\text { Mono }\end{array}$ & 54 & 1 & & 1 & & 2 & & & & & 16 & 10 & 9 & 10 & 1 & & & & & 1 & 3 & & \\
\hline Lassen & 22 & 5 & & 4 & & 8 & & 1 & & & & & & & & & 1 & 1 & 2 & & & & \\
\hline Churchill & 18 & & 2 & & 5 & 8 & 1 & & 1 & 1 & & & & & & & & & & & & & \\
\hline
\end{tabular}


Table 3. Pairwise population ( $\left.F_{S T}\right)$ comparisons using mitochondrial DNA data. Significant differences in bold. [LV, Long Valley; BH, Bodie Hills; WBF, Wheeler Burcham Flat; PM; Parker Meadows, WM, White Mountain; JF, Jackass Flat]

\begin{tabular}{llllllllll}
\hline & LV & BH & WBF & PM & WM & JF & Lyon/Mono & Lassen & Churchill \\
\hline LV & 0.00000 & & & & & & & & \\
BH & -0.00193 & 0.00000 & & & & & & & \\
WBF & -0.05990 & -0.02119 & 0.00000 & & & & & & \\
PM & 0.28577 & 0.13358 & 0.32856 & 0.00000 & & & & & \\
WM & -0.01638 & -0.00528 & -0.04345 & 0.18585 & 0.00000 & & & & \\
JF & -0.02012 & -0.01051 & -0.06952 & 0.28246 & 0.00501 & 0.00000 & & & \\
Lyon/Mono & 0.02762 & -0.01217 & 0.01572 & 0.09189 & 0.00549 & 0.03404 & 0.00000 & & \\
Lassen & 0.19180 & 0.11295 & 0.20876 & 0.07565 & 0.11218 & 0.22727 & 0.06865 & 0.00000 & \\
Churchill & 0.44466 & 0.31622 & 0.52456 & 0.18629 & 0.32359 & 0.47309 & 0.23401 & 0.11481 & 0.00000 \\
\hline
\end{tabular}

Table 4. Genetic diversity measures for microsatellite data. [LV, Long Valley; BH, Bodie Hills; WBF, Wheeler Burcham Flat; PM; Parker Meadows, WM, White Mountain; JF, Jackass Flat]

\begin{tabular}{ccccc}
\hline Sub-population & $\begin{array}{c}\text { Number of } \\
\text { samples }\end{array}$ & Average gene diversity & $\begin{array}{c}\text { Mean number of alleles } \\
\text { per sub-population }\end{array}$ & Allelic richness \\
\hline LV & 18 & 0.5052 & 4.57 & 2.19 \\
BH & 28 & 0.5318 & 4.85 & 2.29 \\
WBF & 7 & 0.3909 & 3.00 & 1.99 \\
PM & 11 & 0.4935 & 3.00 & 2.29 \\
WM & 29 & 0.4189 & 3.28 & 1.99 \\
JF & 14 & 0.4414 & 3.33 & 2.06 \\
\hline
\end{tabular}

Table 5. Pairwise population $\mathrm{F}_{S T}$ comparisons using microsatellite data. Significant differences in bold.

\begin{tabular}{lccccccccc}
\hline & LV & BH & WBF & PM & WM & JF & Lyon/Mono & Lassen & Churchill \\
\hline LV & 0.00000 & & & & & & & & \\
BH & $\mathbf{0 . 0 5 6 5 6}$ & 0.00000 & & & & & & & \\
WBF & 0.09422 & 0.06523 & 0.00000 & & & & & & \\
PM & $\mathbf{0 . 1 0 4 9 8}$ & 0.05377 & -0.05148 & 0.00000 & & & & & \\
WM & $\mathbf{0 . 1 3 8 7 0}$ & $\mathbf{0 . 1 5 2 1 2}$ & $\mathbf{0 . 2 2 8 4 8}$ & $\mathbf{0 . 2 2 8 7 0}$ & 0.00000 & & & & \\
JF & $\mathbf{0 . 1 3 8 9 4}$ & 0.05645 & 0.07741 & $\mathbf{0 . 1 4 0 9 1}$ & $\mathbf{0 . 1 7 1 0 9}$ & 0.00000 & & & \\
Lyon/Mono & 0.01013 & 0.00076 & 0.00488 & 0.03794 & $\mathbf{0 . 1 2 5 1 0}$ & 0.02111 & 0.00000 & & \\
Lassen & $\mathbf{0 . 1 3 4 4 8}$ & $\mathbf{0 . 0 9 8 4 2}$ & $\mathbf{0 . 0 7 4 9 4}$ & $\mathbf{0 . 0 7 9 3 2}$ & $\mathbf{0 . 2 0 1 0 4}$ & $\mathbf{0 . 0 8 8 1 9}$ & $\mathbf{0 . 1 4 1 3 5}$ & 0.00000 & \\
Churchill & $\mathbf{0 . 1 7 3 7 3}$ & $\mathbf{0 . 1 5 8 9 4}$ & $\mathbf{0 . 1 6 0 6 6}$ & $\mathbf{0 . 1 7 2 9 3}$ & $\mathbf{0 . 1 6 2 9 9}$ & $\mathbf{0 . 0 9 6 7 9}$ & $\mathbf{0 . 1 4 7 9 2}$ & $\mathbf{0 . 0 6 9 2 4}$ & 0.00000 \\
\hline
\end{tabular}




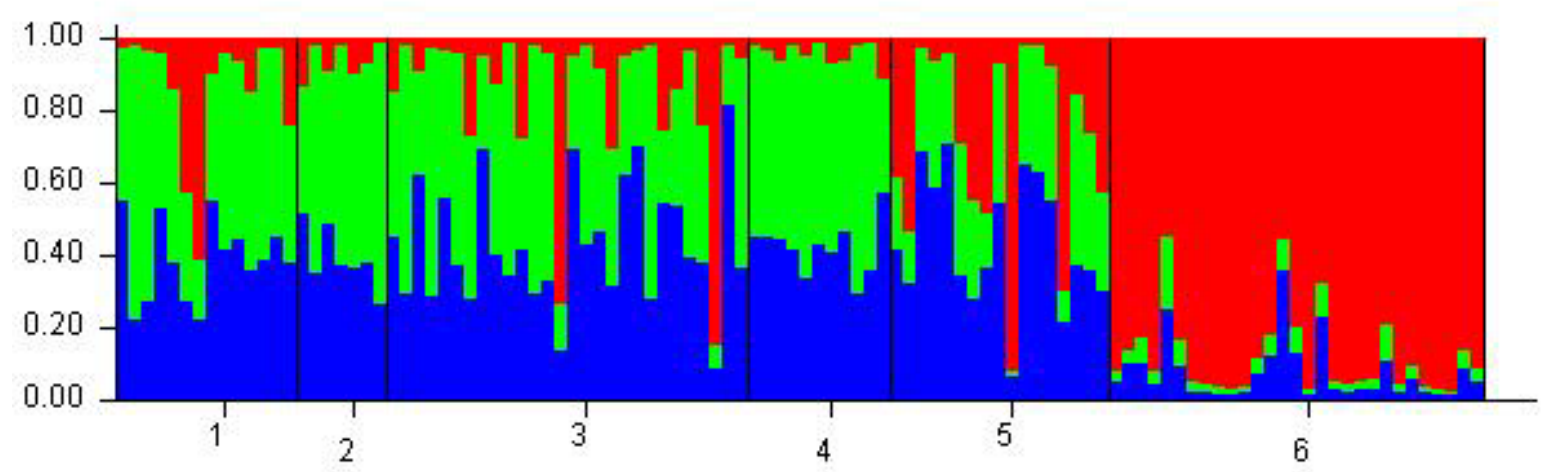

Figure 4. STRUCTURE results for $\mathrm{K}=3$ with populations: (1) Jackass Flat, (2) Wheeler Burcham Flat, (3) Bodie Hills, (4) Parker Meadows, (5) Long Valley, and (6) White Mountains. Subpopulations are shown in order from north to south. Each bar represents an individual sage-grouse. Different colors of the bar represent the probability of belonging to the cluster of that color.

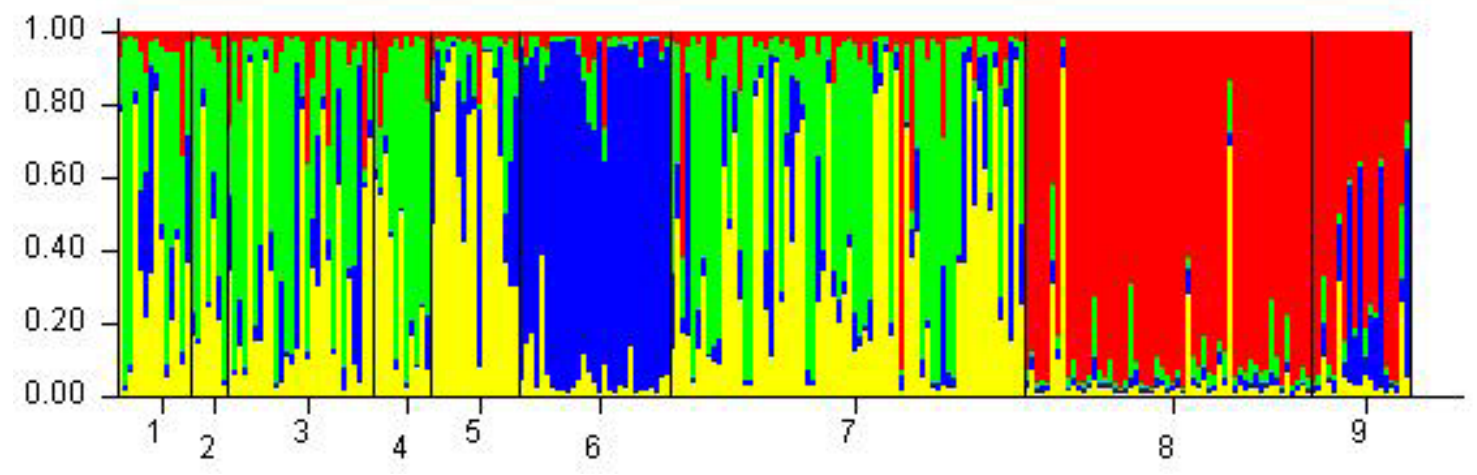

Figure 5. STRUCTURE results for $K=4$ with populations: (1) Jackass Flat, (2) Wheeler Burcham Flat, (3) Bodie Hills, (4) Parker Meadows, (5) Long Valley, (6) White Mountains (7) Lyon/Mono, (8) Lassen, and (9) Churchill. Each bar represents an individual sage-grouse. Different colors of the bar represent the probability of belonging to the cluster of that color.

\section{Conclusion}

The mtDNA analysis revealed that all newly sampled subpopulations contained haplotypes that were consistent within the genetically unique Lyon/Mono Greater Sage-grouse described previously (Benedict and others, 2003; Oyler-McCance and others, 2005a). Specifically, all subpopulations contained individuals with the BM haplotype that is characteristic of the Lyon/Mono birds, and all but one subpopulation had the haplotype BJ represented, which too is considered to be a Bi-State haplotype. Additionally, all but one subpopulation (PM) were found to be significantly different from the Churchill population when comparing mtDNA haplotype frequencies (pairwise $\mathrm{F}_{\mathrm{ST}}$ ). Interestingly, none of the subpopulations were significantly different from the Lassen population at mtDNA frequencies (table 3), yet this may be more reflective of the low power of comparisons using smaller sample sizes, as the $\mathrm{F}_{\text {ST }}$ values themselves are not particularly small. Additionally, Lassen is the closest population that was once connected to the Bi-State (fig. 1). 
Two new haplotypes were found at locales LV and WM that have not previously been described in Greater Sage-grouse (table 2). Both belonged to clade I (fig. 3) yet were only single-base-pair substitutions from existing Bi-State haplotypes BL and BM, which suggests that the new haplotypes are recent mutations from those more common haplotypes. The PM subpopulation had the lowest reported number of haplotypes (two) yet also had the second lowest sample size $(n=13)$. The WM subpopulation also had a lower number of haplotypes (four) with a relatively high sample size $(n=29)$.

Pairwise population $\mathrm{F}_{\mathrm{ST}}$ tests using the microsatellite data reveal that all newly described subpopulations are significantly different from the outside populations of Churchill and Lassen (table 5). However, many of the subpopulations are also significantly different from one another (table 5). The WM subpopulation was the only subpopulation that was significantly different from all others. It is the southernmost subpopulation and is somewhat isolated and at a higher elevation (fig. 2).

The STRUCTURE analysis of the subpopulations revealed that the data are best represented by three distinct genetic clusters and that the WM subpopulation appears to be distinct from the other subpopulations. The STRUCTURE analysis also revealed one potential migrant from the WM area into the neighboring LV area (an individual in the middle of the LV group that is characterized almost completely by the red cluster, fig. 4). When the Lassen and Churchill populations (outside the Bi-State) and data from the original Mono/Lyon birds are included in the STRUCTURE analysis, there are most likely four unique genetic clusters, and the Churchill and Lassen populations are markedly different from all other individual populations (fig. 5). The WM subpopulation does appear to maintain its subdivision, suggesting that it is substantially isolated from the other Bi-State subpopulations (fig. 5).

The number of microsatellite alleles was fairly constant across the newly collected Bi-State subpopulations with BH relatively high (probably due to large sample size or central location in the BiState) and PM and WBF relatively low. When we correct for unequal sample sizes, however, WBF and WM have the lowest allelic richness.

There does appear to be additional subdivision within the Bi-State, particularly with the WM subpopulation. This subpopulation does have some of the typical unique Lyon/Mono haplotypes (BM and DQ) yet lacks the common BJ. More striking is the subdivision that is noted when examining the microsatellite data (table 5, figs. 4 and 5) and when comparing its genetic diversity to other subpopulations in the Bi-State (tables 1 and 4). The WM population of Greater Sage-grouse is uniquely located at the southwestern edge of the species' range at a high elevation location east of the Sierra Nevadas. The average elevation at relocation points for Greater Sage-grouse radio-marked in WM was 3,200 meters $(\mathrm{m}) \pm 220 \mathrm{~m}$ with some individuals commonly found above 3,600 $\mathrm{m}$ (U.S. Geological Survey (USGS), unpublished data). The base of the White Mountain range starts at about 1,300 $\mathrm{m}$ and rises to 4,341 $\mathrm{m}$ atop White Mountain Peak. Sagebrush-dominated vegetation communities are primarily found at the sub-alpine elevation zone between 2,900 m -3,660 m (Mooney and others, 1962). Vegetation on lower elevation slopes $(1,980 \mathrm{~m}$ to $2,900 \mathrm{~m}$ ) is dominated by pinyon (Pinus monophylla) and juniper (Juniperus osteosperma) woodland (pinyon/juniper: PJ). This band of PJ may form a barrier to grouse movement, as Greater Sage-grouse are known to avoid these habitats (Commons and others, 1999; Casazza and others, in press). The closet known subpopulation to the WM population is the LV subpopulation. These subpopulations are at a distance of approximately 60 kilometers $(\mathrm{km})$ apart, and much of the habitat between WM and LV is fragmented and unsuitable for Greater Sagegrouse.

Both the mtDNA and the microsatellite data suggest that the Bi-State Greater Sage-grouse are genetically unique from Greater Sage-grouse elsewhere across the range. This supports previous genetic work using the same microsatellite markers (Benedict and others, 2003; Oyler-McCance and others, 2005a). Both data sets also suggest that the Churchill population is more divergent from the Bi- 
State birds than is the Lassen population. This is not surprising, as the Lassen population was potentially connected to the Bi-State population historically and is now separate because of the loss of habitat connecting them.

As has been suggested previously (Oyler-McCance and others, 2005a), the Bi-State Greater Sage-grouse are genetically unique and warrant special attention. Maintaining the genetic integrity of this population could protect the evolutionary potential of this population of Greater Sage-grouse. Since the two mtDNA monophyletic clades reported by Kahn and others (1999) are not separated geographically and both occur in the Bi-State (Oyler-McCance and others, 2005a), it can be concluded that the Bi-State population became isolated from other sagebrush areas after the two clades, which had previously been separated, were re-joined less than 850,000 years ago (Kahn and others, 1999).

The amount of genetic differentiation between the Bi-State birds is similar to if not greater than the amount of genetic difference between the Gunnison Sage-grouse and neighboring Greater Sagegrouse in Colorado. This genetic differentiation suggests that the Bi-State birds may have been isolated from other Greater Sage-grouse for a similar amount of time. This isolation is likely due to geographic and landscape features (for example, lack of sagebrush habitat) that have been in place since before English settlement (Schroeder and others, 2004). Unlike Gunnison Sage-grouse, however, Bi-State Greater Sage-grouse have not developed the distinct differences in plumage, morphology (C.E. Braun, oral comm.), and behavior (Taylor and Young, 2006) that have led to the reproductive isolation and speciation in Gunnison Sage-grouse.

\section{Acknowledgments}

This report was prepared for the U.S. Fish and Wildlife Service as required by Agreement No. 84320-5-H322 with the USGS. We thank C. Overton, E. Kolada, M. Farinha, and numerous dedicated field technicians from the Western Ecological Research Center of the USGS for collecting samples for this study. Additional samples were provided by S. Espinosa of the Nevada Department of Wildlife and by S. Pellegrini and his students from Yerington High School, Yerington, Nev. Support for sample collection was also provided by Quail Unlimited; the University of Nevada, Reno; the California Department of Fish and Game; the U.S. Forest Service; and the Bureau of Land Management. We thank J. St. John and D. Scherbek for lab assistance and C. Overton and F. Ransler for their helpful comments on this manuscript. 


\section{References Cited}

Benedict, N.G., Oyler-McCance, S.J., Taylor, S.E., Braun, C.E., and Quinn, T.W., 2003, Evaluation of the eastern (Centrocercus urophasianus urophasianus) and western (Centrocercus urophasianus phaios) sub-species of Sage-grouse using mitochondrial control region sequence data: Conservation Genetics, v. 4, p. 301-310.

Braun, C.E., 1998, Sage-Grouse declines in western North America-What are the problems?: Proceedings of the Western Association of State Fish and Wildlife Agencies, v. 78, p. 139-156.

Commons, M.L., Baydack, R.K., and Braun, C.E, 1999, Sage grouse response to Pinyon-Juniper Management, in Monsen, S.B. and Stevens, R., comps., Ecology and management of pinyon-juniper communities within the Interior West, Provo, Utah, September 15-18 1997, Proceedings: Washington D.C., U.S. Department of Agriculture, RMRS-P-9, p. 238-239.

Casazza, M.L., Coates, P.S., and Overton, C.T., in press, Linking habitat selection to brood success in greater sage-grouse-A multi-scale modeling approach: Studies in Avian Biology. Ecology, Conservation and Management of Grouse.

Giesen, K.M., Schoenberg, T.J., and Braun, C.E., 1982, Methods for trapping sage grouse in Colorado: Wildlife Society Bulletin, v. 10, p. 224-231.

Goudet, J., 1995, Fstat version 1.2-A computer program to calculate F statistics: Journal of Heredity, v. 86 , p. $485-486$.

Guo, S., and Thompson, E., 1992, Performing the exact test of Hardy-Weinberg proportions for multiple alleles: Biometrics, v. 48, p. 361-372.

Johnsgard, P.A., 1983, The grouse of the world: Lincoln, Nebr., University of Nebraska Press, 412 p.

Kahn N.W., Braun, C.E., Young, J.R., Wood, S., Mata, D.R., and Quinn, T.W., 1999, Molecular analysis of genetic variation among large and small-bodied sage grouse using mitochondrial controlregion sequences: The Auk, v. 116, p. 819-824.

Mooney, H.A., St. Andre, G., and Wright, R.D., 1962, Alpine and subalpine vegetation patterns in the White Mountains of California: The American Midland Naturalist, v. 68, p. 257-273.

Oyler-McCance, S.J., Taylor, S.E., and Quinn, T.W., 2005a, A multilocus population genetic survey of the greater sage-grouse across their range: Molecular Ecology, v. 14, p. 1293-1310.

Oyler-McCance, S.J., St. John, J., Taylor, S.E., Apa, A.D., and Quinn, T.W., 2005b, Population genetics of Gunnison sage-grouse-Implications for management: Journal of Wildlife Management, v. 69, p. 630-637.

Peakall, R., and Smouse, P.E., 2006, GENALEX 6-Genetic analyses in excel—Population genetic software for teaching and research: Molecular Ecology Notes, v. 6, p. 288-295. 
Pritchard J.K., Stephens, M., and Donnelly, P.J., 2000, Inference of population structure using multilocus genotype data: Genetics, v. 155, p. 945-959.

Tamura K., Dudley, J., Nei, M., and Kumar, S., 2007, MEGA4-Molecular Evolutionary Genetics Analysis (MEGA) software version 4.0: Molecular Biology and Evolution, v. 24, p. 1596-1599.

Taylor S.E., and Young, J.R., 2006, A comparative behavioral study of three Greater Sage-Grouse populations: Wilson Journal of Ornithology, v. 118, p. 36-41.

Schneider S., Roessli, D., and Excoffier, L., 2001, Arlequin-An integrated software for population genetics data analysis Version 2.001: Geneva, Switzerland, University of Geneva, Genetics and Biometry Laboratory, unpaged.

Schroeder M.A., Aldridge, C.L., Apa, A., Bohne, J.R., Braun, C.E., Bunnell, S.D., Connelly, J.W., Deibert, P.A., Gardner, S.C., Hilliard, M.A., Kobriger, G.D., McCarthy, C.W., McCarthy, J.J., Mitchell, D.L., Rickerson, E.V., and Stiver, S.J., 2004, Distribution of Sage Grouse in North America: Condor, v. 106, p. 363-376.

Publishing support provided by: Denver Publishing Service Center

For more information concerning this publication, contact:

Center Director, USGS Fort Collins Science Center

2150 Centre Ave., Bldg. C

Fort Collins, CO 80526-8118

(970) 226-9398

Or visit the Fort Collins Science Center Web site at: http://www.fort.usgs.gov/ 